\title{
FLIPI Score 0-1, Low Risk
}

National Cancer Institute

\section{Source}

National Cancer Institute. FLIPI Score 0-1, Low Risk. NCI Thesaurus. Code C136965.

A score indicating that a patient has 0 or 1 risk factors associated with follicular lymphoma and is considered in the low risk group. 